\title{
APLICAÇÃo DE POTÁSSIO NA PRODUÇÃO DE CAMOMILA (Chamomilla recutita)
}

Bruna Barbosa dos Santos ${ }^{1}$, Volnei Pauletti ${ }^{2}$, Luciano Antunes da Roza ${ }^{3}$, Rodrigo Weiss da Silva ${ }^{4}$

\author{
${ }^{1}$ Acadêmica do curso de Agronomia, UFPR; bruna.santos90@gmail.com \\ ${ }^{2}$ Professor, Departamento de Solos e Engenharia Agrícola, UFPR; vpauletti@ufpr.br; \\ ${ }^{3}$ Mestrando, Programa de Pós-Graduação em Ciência do Solo, UFPR; lucianoantunes6@ gmail.com \\ ${ }^{4}$ Engenheiro Agrônomo, Mestre, CDA Agrícola; solosrws@gmail.com
}

RESUMO A camomila (Chamomilla recutita L. Rauschert) é uma planta medicinal de reconhecido valor, por seus compostos secundários utilizados na indústria de cosméticos e medicamentos, além de seu consumo in natura. A camomila possui propriedades calmantes, analgésicas e aromáticas, e é consumida no mundo todo. $\mathrm{O}$ Paraná é o líder de produção de camomila do Brasil, porém com baixas produtividades. A adubação nesta espécie é pouco estudada e geralmente avaliada com a aplicação de adubos orgânicos, o que dificulta o entendimento da influência de cada nutriente na produtividade e qualidade da camomila. Dados sobre a adubação com potássio na camomila, um dos nutrientes mais exigidos, são quase inexistentes, especialmente nas condições brasileiras de cultivo. O presente experimento teve como objetivo verificar a produtividade e as características dos capítulos florais de camomila, em função da aplicação de potássio em condições de campo. Apesar de ter aumentado o número de ramos por planta, a aplicação de potássio não alterou a produtividade e as características dos capítulos florais da camomila.

Palavras-chave: planta medicinal, adubação potássica, capítulos florais, cultivar mandirituba.

\section{POTASSIUM APPLICATION ON CHAMOMILE PRODUCTION (Chamomilla recutita)}

\begin{abstract}
Chamomile (Chamomilla recutita L. Rauschert) is a medicinal plant of recognized value for their secondary compounds used in the cosmetic and pharmaceutical industry, as well as its fresh consumption. Chamomile has calming, analgesic and aromatic properties, and is consumed worldwide. Paraná is the chamomile production leader Brazil, but with low productivity. The fertilization in this species is poorly studied and generally evaluated with the application of organic fertilizers, which
\end{abstract}


hinders the understanding of the influence of each nutrient in productivity and chamomile quality. Data on the fertilizer with potassium in chamomile, one of the required nutrients, are almost nonexistent, especially in Brazilian growing conditions. The present study aimed to verify the productivity and characteristics of capitula of chamomile, due to potassium application in field conditions. Despite having increased the number of branches per plant, the application of potassium did not change the productivity and characteristics of flower heads of chamomile.

Key words: medicinal plant, potassium fertilization, flowering capitula, cultivate Mandirituba.

\section{INTRODUÇÃO}

A camomila (Chamomilla recutita), pertence à família Asteraceae e é a planta medicinal mais cultivada no mundo, contendo compostos farmacológicos como ácidos orgânicos, cumarinas, flavonoides, terpenos, entre outros (RODRIGUEZ et al., 1996; SILVA JÚNIOR, 2003).

O estado do Paraná contribui com aproximadamente $60 \%$ da produção de camomila do Brasil, e seu sistema envolve cerca de 850 produtores, sendo que alguns destes tem uma produção comercial significativa, enquanto outros são pequenos e médios produtores, sem muito acesso à tecnologia e autonomia na produção (CORRÊA; ALVES, 2008). No entanto, a média de produtividade $\left(500 \mathrm{~kg} \mathrm{ha}^{-1}\right)$ e de qualidade da camomila produzida no Paraná é inferior à de outros países produtores, como a Argentina (700 a $800 \mathrm{~kg} \mathrm{ha}^{-1}$ ) (CARATI, 2006). Isso se explica pela baixa tecnologia aplicada à produção, e por aspectos fundamentais, como o manejo da adubação, serem pouco considerados.

A qualidade da camomila está ligada a produção de metabólitos secundários, que também é influenciada por uma boa nutrição, pois dá à planta condições de translocar os nutrientes para produzir os compostos de interesse.

Nas plantas, o potássio é um importante cofator enzimático, é o principal cátion envolvido no controle do potencial osmótico interno, e importante para manutenção da eletroneutralidade, atuando livre no tecido vegetal, ou ligado a compostos produzidos na fotossíntese (TAIZ; ZEIGER, 2006). 
Trabalhos em condições brasileiras com adubação em camomila são poucos e geralmente utilizam estercos (RAMOS et al., 2004; NALEPA; CARVALHO, 2007; AMARAL et al., 2008; VIEIRA et al., 2009) ou vinhaça (ANTUNES et al., 2009), o que dificulta o entendimento de qual nutriente está ocasionando o efeito obtido. Naderidarbaghshahi et al. (2012), no Irã, observaram efeito negativo da aplicação de potássio na produção de óleo, porém, em combinação com nitrogênio e fósforo, o efeito foi positivo.

Este trabalho teve como objetivo verificar a produtividade e as características dos capítulos florais da camomila, sob diferentes doses de potássio.

\section{MATERIAL E MÉTODOS}

O experimento foi realizado no município de São José dos Pinhais, região metropolitana de Curitiba, em área de produtor, localizada nas coordenadas Lat $25^{\circ} 38^{\prime}$ 49' S e Long 49 11' 28', W, em altitude de 918 metros. O clima local é classificado como subtropical úmido de acordo com Köppen-Geiger (KOTTEK et al., 2006). O solo do local do experimento apresentou características químicas adequadas para a camomila (Tabela 1) (SOCIEDADE ..., 2004).

Tabela 1. Análise química do solo na camada de 0-20 cm, no local do experimento, antes da implantação.

Table 1. Chemical analysis of soil at $0-20 \mathrm{~cm}$ in the place of the experiment, before deployment.

\begin{tabular}{|c|c|c|c|c|c|c|c|c|c|}
\hline $\mathrm{pH}$ & $\mathrm{Al}^{+3}$ & $\mathrm{Ca}^{+2}$ & $\mathrm{Mg}^{+2}$ & $\mathrm{~K}^{+}$ & SB & $\mathrm{T}$ & $\mathrm{P}$ & $\mathrm{C}$ & V \\
\hline $\mathrm{CaCl}_{2}$ & & & $\mathrm{~mol}_{\mathrm{c}} \mathrm{d}$ & & & & $-\mathrm{gd}$ & $\mathrm{n}^{-3}$ & $\%$ \\
\hline 5,6 & 0 & 7.5 & 4.4 & 0,24 & 12,14 & 17.14 & 11.6 & 27.1 & 71 \\
\hline
\end{tabular}

A cultivar utilizada foi a Mandirituba, que é largamente utilizada na região. A semeadura foi realizada em 20/05/2013, com cerca de $2 \mathrm{Kg}$ de sementes viáveis por hectare, com aplicação a lanço, usando uma espalhadora de calcário. 
O delineamento estatístico utilizado foi o de blocos casualizados, com os tratamentos correspondendo à cinco doses de potássio $\left(0,30,60,90 \mathrm{e} 120 \mathrm{~kg} \cdot \mathrm{ha}^{-1}\right.$ de $\mathrm{K}_{2} \mathrm{O}$ ), em forma de $\mathrm{KCl}$, com quatro repetições. Cada parcela apresentou área de $6 \mathrm{~m}^{2}$ ( $2 \times 3 \mathrm{~m})$ sendo área útil de $2 \mathrm{~m}^{2}(1 \times 2 \mathrm{~m})$. Os tratamentos foram aplicados a lanço, em cobertura, aos 37 dias após a semeadura (DAS). Todas as parcelas receberam aplicação de $80 \mathrm{~kg} \mathrm{ha}^{-1}$ de $\mathrm{N}$ em cobertura em forma de ureia no mesmo dia da aplicação dos tratamentos.

Aos 60 DAS foi realizada a contagem da população de plantas, dentro da área útil, com o uso de dois quadrados com área de $0,25 \mathrm{~m}^{2}$ e extrapolando os valores para estimar a população por hectare. Aos 127 DAS foi realizada a colheita de toda a área útil determinando-se a produtividade de massa seca (MS) de capítulos. Foram coletados os capítulos, incluindo cerca de 2 a $3 \mathrm{~cm}$ de pedúnculo, que após secagem em estufa a $45^{\circ} \mathrm{C}$, até peso constante, foram pesados e o resultado extrapolado para produtividade por hectare. No momento da colheita, foram separadas e coletadas aleatoriamente 10 plantas da área útil da parcela, cortando-se a aproximadamente um $\mathrm{cm}$ da superfície do solo, para determinação da altura das plantas (medindo-se a haste principal do ponto de corte até a ponta) e contagem do número de ramos, perfilhos e de capítulos por planta. Também foram determinadas a largura da haste principal das 10 plantas, medindo-se a haste a aproximadamente $2 \mathrm{~cm}$ do ponto de corte, e a altura e largura de 50 capítulos, com auxílio de paquímetro. Os capítulos medidos foram escolhidos ao acaso entre os coletados com as 10 plantas utilizadas para contagem de ramos e capítulos.

Os dados obtidos foram avaliados quanto à distribuição normal pelo teste de Bartllet, e posteriormente submetidos a análise de regressão.

\section{RESULTADOS E DISCUSSÃO}

Não houve efeito da aplicação de potássio sobre a altura de plantas, diâmetro de haste, número de perfilhos, altura e diâmetro de capítulos, número de capítulos, massa seca e produtividade (Tabela 2). 
Tabela 2. Altura de plantas (AltP), diâmetro de haste (Dhaste), número de perfilhos (NPerf) e altura (AltCap), diâmetro (DCap), número de (NCap), massa seca (Mseca) e produtividade (Prod.) de capítulos de Chamomilla recutita, cultivar Mandirituba, em função da aplicação de potássio.

Table 2. Plant height (AltP), stem diameter (Dhaste), tillers number (NPerf) and height (AltCap), diameter (DCap), number (NCap), dry matter (Mseca) and yield (Prod) of flower heads Chamomilla recutita, cultivar Mandirituba, according potassium application.

\begin{tabular}{ccccccccc}
\hline $\mathrm{K}_{2} \mathrm{O}$ & AltP & Dhaste & Nperf & AltCap & Dcap & NCap & Mseca & Prod. \\
\hline $\mathrm{kg} \mathrm{ha}^{-1}$ & $\mathrm{~cm}$ & $\mathrm{~mm}$ & & $\mathrm{~mm}$ & $\mathrm{~mm}$ & & $\mathrm{~g}$ & $\mathrm{~kg} \mathrm{ha}^{-1}$ \\
0 & $45,34 \mathrm{a}$ & $3,11 \mathrm{a}$ & $0,9 \mathrm{a}$ & $7,40 \mathrm{a}$ & $6,91 \mathrm{a}$ & $235 \mathrm{a}$ & $180,69 \mathrm{a}$ & $451,7 \mathrm{a}$ \\
30 & $47,63 \mathrm{a}$ & $3,06 \mathrm{a}$ & $0,7 \mathrm{a}$ & $7,68 \mathrm{a}$ & $6,64 \mathrm{a}$ & $239 \mathrm{a}$ & $161,75 \mathrm{a}$ & $404,7 \mathrm{a}$ \\
60 & $45,41 \mathrm{a}$ & $3,40 \mathrm{a}$ & $1,2 \mathrm{a}$ & $7,66 \mathrm{a}$ & $6,96 \mathrm{a}$ & $250 \mathrm{a}$ & $125,31 \mathrm{a}$ & $313,9 \mathrm{a}$ \\
90 & $50,22 \mathrm{a}$ & $3,67 \mathrm{a}$ & $1,3 \mathrm{a}$ & $7,83 \mathrm{a}$ & $7,07 \mathrm{a}$ & $392 \mathrm{a}$ & $162,63 \mathrm{a}$ & $406,6 \mathrm{a}$ \\
120 & $46,35 \mathrm{a}$ & $3,12 \mathrm{a}$ & $0,7 \mathrm{a}$ & $7,09 \mathrm{a}$ & $6,61 \mathrm{a}$ & $207 \mathrm{a}$ & $165,17 \mathrm{a}$ & $412,9 \mathrm{a}$ \\
\hline $\mathrm{R}^{2}$ & $0,13 \mathrm{~ns}$ & $0,14 \mathrm{~ns}$ & $0,02 \mathrm{~ns}$ & $0,06 \mathrm{~ns}$ & $0,04 \mathrm{~ns}$ & $0,04 \mathrm{~ns}$ & $0,05 \mathrm{~ns}$ & $0,65 \mathrm{~ns}$ \\
\hline
\end{tabular}

O teor alto de potássio no solo de $0,24 \mathrm{cmol}_{\mathrm{c}} \mathrm{dm}^{-3}$ (Tabela 1) pode ter sido o principal motivo da ausência de efeito da aplicação deste nutriente na camomila. Nestes casos, a recomendação de adubação potássica é de menos de $20 \mathrm{~kg} \mathrm{ha}^{-1}$ de $\mathrm{K}_{2} \mathrm{O}$ (SOCIEDADE..., 2004). No entanto, a média pluviométrica registrada para o mês de junho, quando foi feita a aplicação dos tratamentos, e no mês seguinte, foram de 300 e $180 \mathrm{~mm}$, respectivamente, muito superiores aos 220 e $130 \mathrm{~mm}$ em 2012 e 200 e $50 \mathrm{~mm}$ em 2014 (INMET, 2015). Esta condição, somada à aplicação do potássio a lanço em cobertura e em aplicação única, é favorável à perda por lixiviação deste nutriente. Portanto, a ausência de efeito da aplicação do potássio indica que estas perdas foram baixas não influenciando na disponibilidade em quantidades suficientes para a cultura ou que a maior dose aplicada não foi suficiente para repor as perdas.

Em outros trabalhos também não foram observados efeitos da adubação na camomila na produtividade de massa seca e quantidade de óleo essencial, discutidas como sendo mais ligadas a características genéticas do que a variações das condições do ambiente. Vieira et al. (2009), com produtividade semelhante obtida em experimento 
utilizando adubação com cama de frango na mesma cultivar Mandirituba, não observaram diferença na produção de massa seca, número de capítulos e altura das plantas com doses que variaram de 1 a $19 \mathrm{t} \mathrm{ha}^{-1}$, correspondendo a 29 a $554 \mathrm{Kg} \mathrm{ha}^{-1}$ de $\mathrm{K}_{2} \mathrm{O}$. Ramos et al. (2004) também não verficaram diferença nas características dos capítulos florais de camomila cv. Mandirituba, porém a produção de massa seca de capítulos foi maior (1.080 kg.ha $\left.{ }^{-1}\right)$ no tratamento com a maior dose de cama de frango correspondente à $1108 \mathrm{~kg} \mathrm{ha}^{-1}$ de $\mathrm{K}_{2} \mathrm{O}$, mesmo com nível alto de $\mathrm{K}$ no solo. Esta produtividade mais elevada obtida com alta dose de potássio, pode ser em parte devida a colheita ter sido feita pelos autores desde os 52 até os 122 DAS, enquanto no presente trabalho foi feita unicamente aos 127 DAS. Como a maturação dos capítulos é desuniforme, parte da produção pode não ter sido avaliada.

Nalepa e Carvalho (2007), também observaram aumento linear da produção de massa fresca e seca de capítulos da cultivar Mandirituba, com o maior rendimento de massa seca de 471,8 $\mathrm{kg} \mathrm{ha}^{-1}$ obtido com a aplicação de $12,5 \mathrm{~kg} \mathrm{~m}^{-2}$ de cama de frango

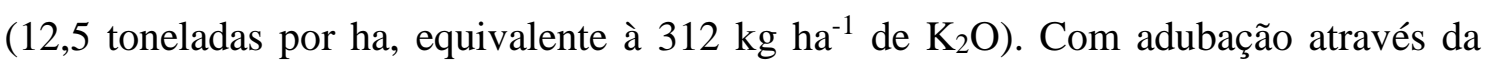
vinhaça, Antunes et al. (2009) obtiveram respostas quadráticas à aplicação, com a maior massa seca obtida com a aplicação de $80 \mathrm{~m}^{3} \mathrm{ha}^{-1}$ (correspondente à 137,08 kg ha ${ }^{-1}$ de $\left.\mathrm{K}_{2} \mathrm{O}\right)$.

Resultados negativos da adubação potássica foram observados por Naderidarbaghshahi et al. (2012), em camomila Alemã (Matricaria chamomilla) que ao aplicarem $50 \mathrm{~kg} \mathrm{ha}^{-1}$ de sulfato de potássio obtiveram menor número e massa seca de capítulos. Porém a aplicação conjunta do potássio com o nitrogênio e fósforo foi benéfica para a produção.

Em outras espécies medicinais, as respostas à adubação também não são frequentes. Araújo et al. (2011) não observaram diferença na produção de massa seca e diminuição da área foliar e do número de internódios em manjericão (Oncimum basilicum) avaliando doses de potássio em cultivo protegido. Segundo os autores, a adição de potássio não foi benéfica devido ao alto nível do nutriente no solo utilizado. 
Em chambá (Justicia pectoralis var. stenophylla), Bezerra et al. (2006) concluíram que a aplicação de esterco bovino e adubos minerais não afetou a produção de biomassa, nem o seu crescimento.

O número de ramos aumentou linearmente com o aumento da dose de potássio (Figura 1). Isso pode ser devido à conhecida participação do potássio no processo de fotossíntese, podendo ter contribuído com o acúmulo de massa seca e potencial de crescimento vegetativo, conforme também foi observado por May et al. (2005), em experimento com Curcuma longa.

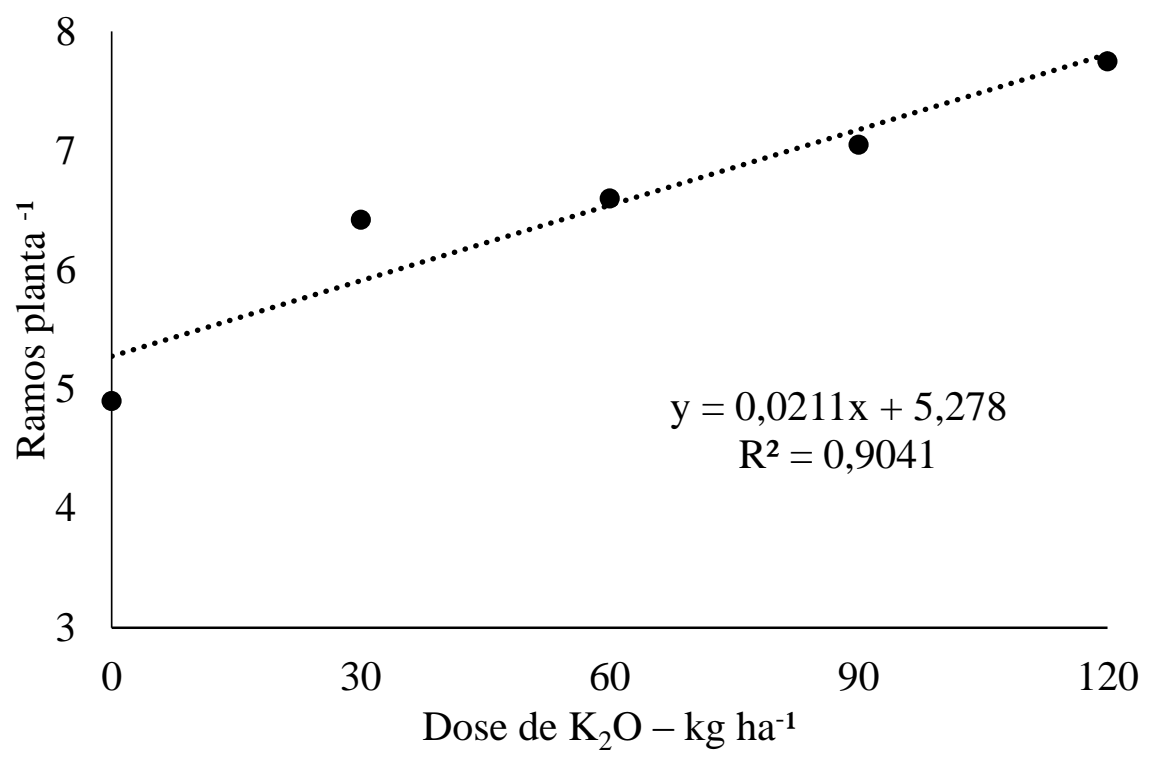

Figura 1. Número médio de ramos por planta de camomila em função das doses de potássio.

Figure 1. Average number of branches per Chamomile plant according potassium doses.

O maior número de perfilhos proporcionou maior número de capítulos (Figura 2), porém não houve correlação entre o número de perfilhos ou de capítulos e a produtividade. 


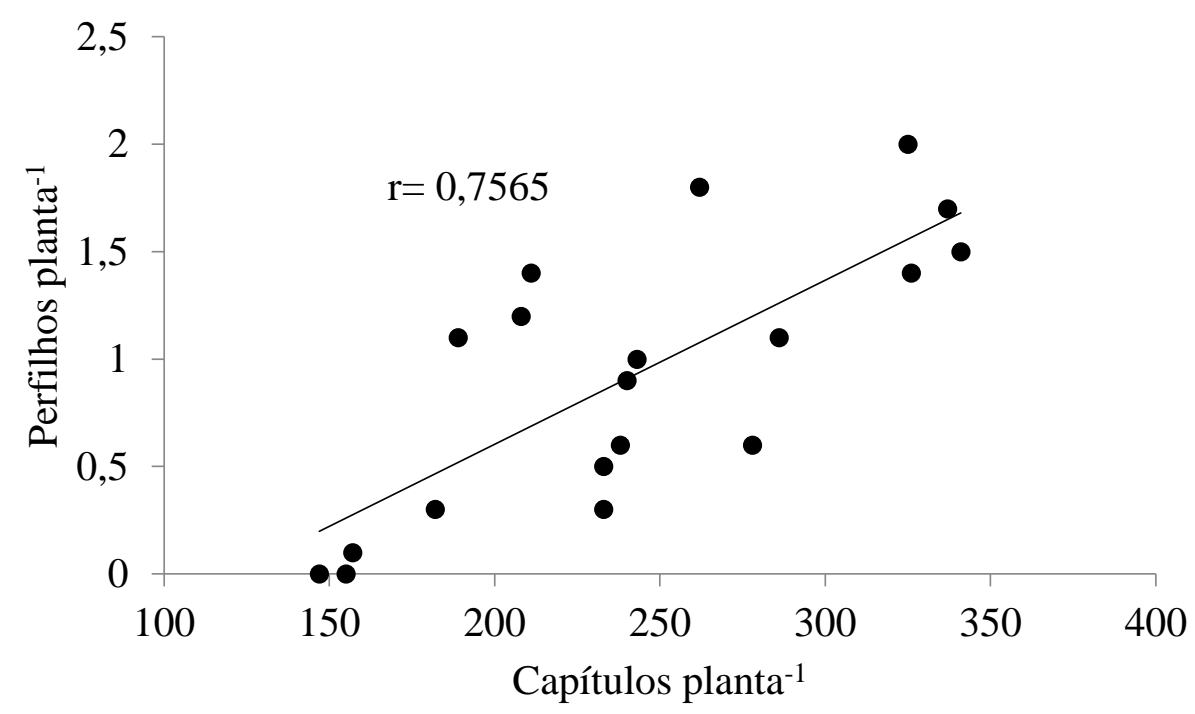

Figura 2. Correlação entre número de perfilhos e número de capítulos por planta de camomila, cultivar Mandirituba.

Figure 2. Correlation between number of tillers and number of flower heads by chamomile plant, cultivar Mandirituba.

O potássio está diretamente envolvido ativação de enzimas, na síntese de proteínas, controle osmótico das células e abertura e fechamento dos estômatos, além de estar envolvido na fotossíntese e no transporte de carbodratos (HAWKESFORD et al., 2012). Portanto, é possível que o aporte de potássio contribua para maior translocação de fotoassimilados na camomila, tornando possível seu melhor desenvolvimento, com maior número de ramos e consequente acréscimo no número de capítulos.

Como neste trabalho foi avaliado apenas uma colheita, é possível que o maior número de ramos por planta proporcionado pela adubação potássica possa aumentar o número de perfilhos e, consequentemente, a produtividade de capítulos numa segunda colheita, prática comum entre os produtores.

\section{CONCLUSÃO}

A adubação potássica não alterou a produtividade e as características dos capítulos florais de Chamomilla recutita, mas aumentou o número de ramos por planta. 


\section{REFERÊNCIAS}

AMARAL, W. et al. Desenvolvimento, rendimento e composição de óleo essencial de camomila [Chamomilarecutita (L.) Rauschert] sob adubação orgânica e mineral, Revista Brasileira de Plantas Medicinais, v.10, n.4, p.1-8, 2008.

ANTUNES, L. J. et al. Efeito da vinhaça na produção de biomassa e óleo essencial de camomila (Chamomila recutita (L.) Rauschert). Revista Saúde e Pesquisa, v. 2, n. 3, p. 333-336, 2009.

ARAÚJO, G. S. et al. Crescimento de manjericão conduzido em cultivo protegido condicionado às doses de nitrogênio e doses supra-ótimas potássio. Ambiência Revista do Setor de Ciências Agrárias e Ambientais. v. 7, n. 2, p. 265-277, 2011.

BEZERRA, A. M. E. et al. Rendimento de biomassa, óleo essencial, teores de fósforo e potássio de chambá em resposta à adubação orgânica e mineral. Revista Ciências Agronômicas. v.37, n.2, 124-129, 2006.

CORREA, C. C.; ALVES, A. F. Plantas Medicinais como alternativa de negócios: caracterização e importância. XLVI Congresso da Sociedade Brasileira de Economia, Administração e Sociologia Rural. Rio Branco, Acre. 2008.

KOTTEK, M. et al. World Map of KöppenGeiger Climate Classification updated. Meteorol. Z., 2006.

HAWKESFORD et al. Functions of macronutrients. In: MARSCHNER, H. Mineral Nutrition of Higher Plants. 3 ed. San Diego: Academic Press. p.135-189, 2012.

MAPELI, N. C. et al. Produção de biomassa e de óleo essencial dos capítulos florais da camomila em função de nitrogênio e fósforo. Horticultura Brasileira, v.23, n.1, p.327, 2005.

MAY, A. et al. Desenvolvimento e produtividade da cúrcuma (Curcuma longa L.) em função de doses de nitrogênio e potássio. Revista Brasileira Plantas Medicinais. Botucatu, v.7, n.3, p 72-78, 2005. 
NADERIDARBAGHSHAHI M. et al. Effects of different levels of nitrogen, phosphorus and potassium fertilizers on some agromorphological and biochemical traits of German chamomile (Matricaria chamomilla L.). Journal of Medicinal Plants Research. v. 6, n. 2, p. 277-283, 2012.

NALEPA, T.; CARVALHO, R. I. N. Produção de biomassa e rendimento de óleo essencial em Camomila cultivada com diferentes doses de cama de aviário. Scientia Agraria. v. 8, n. 2, p. 161-167, 2007.

RAMOS, M. B. M. et al. Produção de capítulos florais em função de populações de plantas e da incorporação ao solo de cama-de-aviário. Horticultura Brasileira, Brasília, v.22, n.3, p. 566-572, 2004.

RODRIGUEZ, F.M.; MOURELLE, J.F.; GUTIÉRREZ, Z.P. Acitivdad espasmolitica del extracto fuido de Matricaria recutita (Manzanilla) en organos aislados. Revista Cubana de Plantas Medicinales, Habana, v.1. n.1, p. 19-24, 1996.

SOCIEDADE Brasileira de Ciência do Solo. Comissão de Química e Fertilidade do Solo. Manual de adubação e de calagem para os Estados do Rio Grande do Sul e de Santa Catarina. - 10. ed. - Porto Alegre, 2004. 400p.

SILVA JÚNIOR, A.A. Essentia herba: plantas bioativas. v.1. Florianópolis: EPAGRI, 2003. 441p.

TAIZ, L.; ZEIGER, E. Fisiologia vegetal. 3.ed. Porto Alegre: Artmed, 2004. 719p. 